\title{
A novel cause of a pressure palsy: mobile telephone user's shoulder droop
}

Position of the mobile telephone.

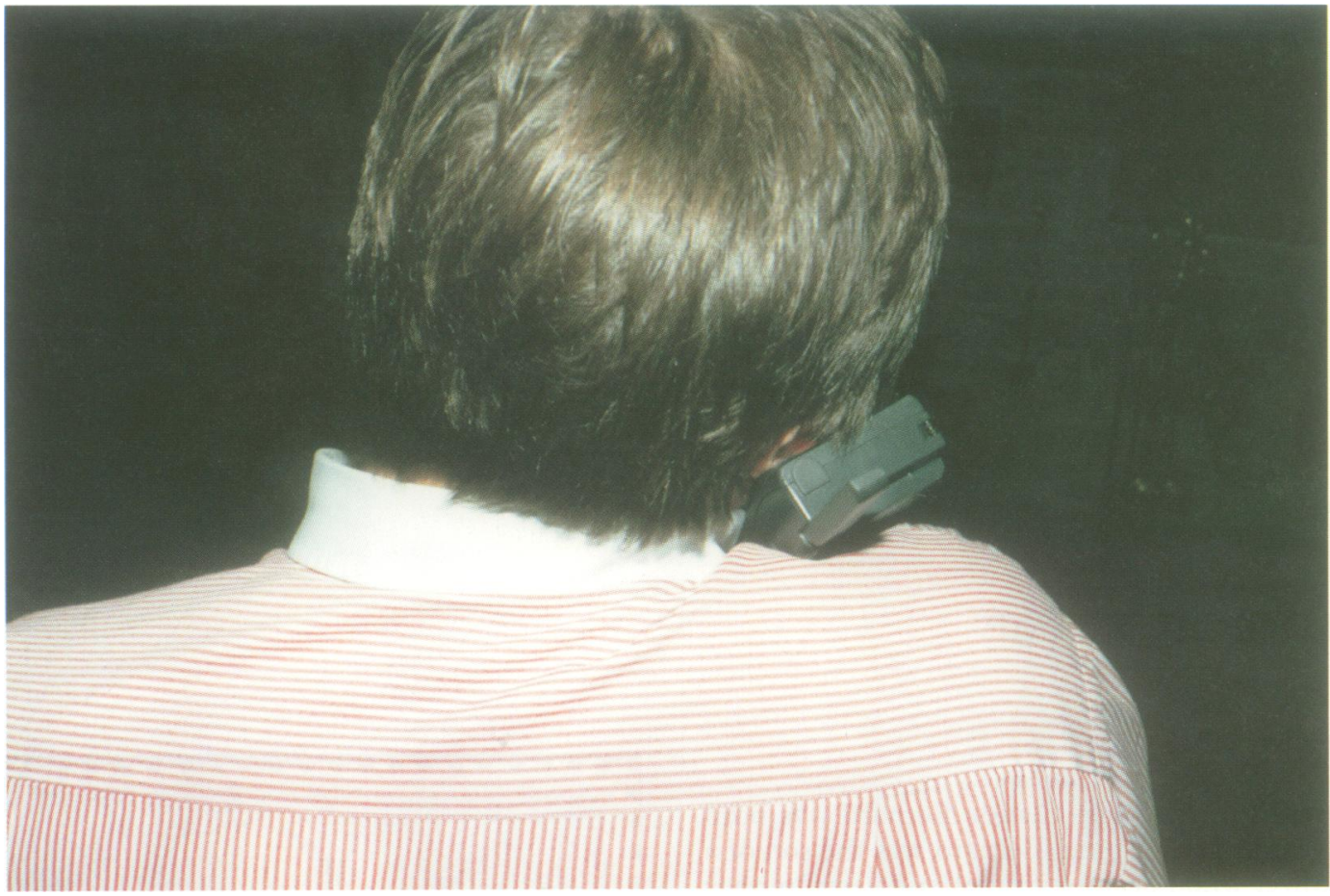

A right handed man, aged 49, found that he was unable to hitch up his shoulder to put his hand in his jacket pocket. Examination showed weakness of the right supraspinatus and right infraspinatus muscle, both supplied by the suprascapular nerve. There was no other muscular weakness, and no sensory disturbance. He remembered that immediately before the onset of these symptoms he had driven for about two hours speaking on his mobile telephone, the telephone being cradled between his right ear and his right shoulder (figure). He was advised not to use his telephone in this way, and his symptoms resolved over four weeks. It seems probable that this nerve was directly compressed by the hard edge of the mobile telephone. ${ }^{1}$

I am grateful to my patient, who suggested the cause for his symptoms, and for providing the photograph. 